\title{
3. Computational stylometry: predicting the authorship of investment arbitration awards
}

Malcolm Langford, Daniel Behn and Runar Lie

\section{INTRODUCTION}

The authorship of judicial opinions was an early target of computational legal studies (Oldfather et al., 2012). Principally focused on the US Supreme Court, different methods were deployed to identify the role of "unseen actors" in writing opinions. Motivated normatively by concerns about the disproportionate influence of clerks in "judicial ghostwriting" (Rosenthal and Yoon, 2011) and theoretically by an interest in the allocation and optimization of time in judicial labour (Choi and Gulati, 2005), research has sought to detect who are the authors of judgments, examine how they are influenced by unseen actors, and chart what variation exists across judges, actors and time.

The methodology is grounded in stylometry, a linguistic theory premised on human authors leaving fingerprints in their writing and a method based on the statistical analysis of measurable patterns particular to literary style. Early stylometry focused on the prominence of "function words" (such as "a", "by", "if", "of" "their" and "who"), which were viewed as the most discernible textual fingerprint. The method permitted ground-breaking qualitative research in identifying authorship, among other things, of the Federalist Papers (Mosteller and Wallace, 1964), by focusing on the use of and placing of 63 function words. Others have sought to identify the authors of books of the Christian Bible (Morton and McLeman, 1966; Burns, 2006) and Shakespearean plays (Seletsky et al., 2007).

This "supervised" approach to stylometry is backed by neurological studies, which show that preferences for function words develop late in children and that function and content words are stored and processed in different brain regions (Menn and Obler, 1990; King and Kutas, 1995). However, in stylometry theory, emphasis is also placed on features like word and sentence length, lexical frequencies, punctuation patterns, rare 
words and the first word in a sentence. Indeed, the origins of stylometry date at least back to 1851 when Augustus de Morgan suggested in a letter that questions of authorship might be settled by determining if a text "does not deal in longer words" (Morgan, 1882).

Computational methods arrived early in the pursuit of stylometric detection (Holmes, 1998). Automated text analysis methods provided a powerful tool due to the speed in which diverse patterns in large quantities of text can be quickly analysed (Oldfather et al., 2012, p. 1206). This computational research was extended to legal documents in a number of analyses of the US Supreme Court, with the function word approach proving popular. Rosenthal and Yoon's (2011) model tested the distribution of the observed count of 63 function words of all opinions of 40 justices over time against a theoretical or expected distribution. The latter was created through the generation of 200 pseudo-documents with 2,000 randomly generated words, in which the probability of a non-function word was 70 per cent and a function word 30 per cent. The null hypothesis was a "V-score" of 1 , calculated through a chi-squared analysis. The authors found significant variation in the consistency across judgment periods for some judges. V-scores ranged from 2.11 to 3.85 , and individual justice scores corresponded with a number of anecdotal observations and clerks' stories over which judges delegated authorship to clerks.

Using 307 function or "non-content" words, Carlson, Livermore and Rockmore (2016) analysed 25,407 opinions of the Supreme Court from 1791 to 2008 to analyse trends in style. They find that there is a "style of the time": judges are more stylistically similar to their peers than to temporally remote justices (ibid., p. 1461). Their results also confirm and extend the findings of Rosenthal and Yoon. Comparing two different measures of stylistic consistency, intra-year on the bench and inter-year for individual judges across time, they find that the "writing styles of individual Justices have become less consistent as clerks have taken on a greater role on the Court" (ibid., p. 1461).

In the earliest known study, Wahlbeck, Spriggs and Sigelman (2002) used instead a broader repertoire of style (eight stylistic features) although with a smaller dataset. Analysing 71 opinions during the 1985 term that were authored by Justices Powell and Marshall, they found, as expected, that Powell's clerks enjoyed less autonomy. Bodwin, Rosenthal and Yoon (2013) also drill down on particular justices, focusing on the hard case of Justice Easterbrook, known for jealously guarding authorship of his own sole authored opinions, but permitting clerks - as they mature - to be more involved in the drafting of his majority opinions. Here, by applying measures of function words, rare words, punctuation and principal com- 
ponent analysis, the researchers were able to detect a distinction between Easterbrook's sole authored and majority opinion texts.

In the last two years, three new studies (including this chapter on investment arbitration) have sought independently to advance computational stylometry. ${ }^{1}$ While dramatically different in their research agendas, they share some commonalities. The first is to move systemically beyond function words to embrace a broader range of stylometric fingerprints. The second is to experiment with different stylometric software packages. ${ }^{2}$ The third is to seek to build stylometric models for individual adjudicators on independent writing and oral material and subsequently test the model against actual decisions.

This latter iteration is certainly the most challenging. However, building independent individual stylometric models is promising for two reasons. It permits machine learning in different forms and is necessary for analysing joint opinions or decisions where authorship is even less certain. Joint decisions are a typical feature in many national and international courts and in various types of arbitration. A single judicial author cannot be identified - at least formally - and depending on the type of adjudicative body, a great degree of variation is thus to be expected theoretically. Given the focus in this chapter on the application of stylometric analysis to the decisions of international courts and tribunals - specifically investor-state arbitration, predictive models based on training sets of texts attributed to individual judges or arbitrators (i.e., texts from sole authored academic journal articles) will provide arguably a surer means at getting at the origins of authorship.

In light of this literature on judicial authorship, this chapter seeks to examine new advances in computational stylometry which focus on a broad range of fingerprints, use of new software, and greater incorporation of machine learning approaches. The remainder of this chapter proceeds as follows. Section 2 examines the arrival of new machine learning logics within stylometry and why it is particularly relevant to studying our field of interest: investor-state arbitration. Section 3 sets out the context for the domain-specific study on investor-state arbitration, section 4 explains our method, including our chosen software, and section 5 our results.

1 The other two are Pauwelyn and Pelc (2019) and Dickinson (2019).

2 With the exception of Dickinson (2019). 


\section{MACHINE LEARNING, STYLOMETRY AND INTERNATIONAL INVESTMENT LAW}

\subsection{Building Individual Stylometric Models}

The first fully fledged machine learning analysis within stylometry was arguably the use of neural networks in 1996 to analyse the Federalist Papers. Tweedie, Singh and Holmes (1996) point out that neural networks are well suited to stylometry given their comparative advantage in recognizing the "underlying organisation" of data. Neural networks can learn from data, generalize, capture non-linear interactions between input variables and are capable of fault tolerance (ibid., p. 2). With a focus on function words, the authors use the 54 undisputed separate papers by Madison and Hamilton as a training and testing set to determine the authorship of the 15 joint and disputed papers. They confirmed existing scholarship that Madison was the author of the disputed papers and analyse shares of the joint papers.

Within law, Rosenthal and Yoon (2011) use machine learning logic to test the robustness of their chi-squared results. For example, in their study of 40 justices of the US Supreme Court, they partitioned the data into a training set and a testing set. Working with pairs of justices, the training set is used to develop a model for classifying judgments as being authored by either Justice "A" or Justice "B". Using a linear classifier based on function words, ${ }^{3}$ they test whether the algorithm predicts the remaining judgments correctly of both judges; and repeat the training and testing process for every single judgment of the two pairwise judges. They found that the classifier could distinguish fairly strongly between judges even when their V-scores for function word distribution were similar. However, the analysis is not used to draw stylometric conclusions about who wrote a decision or test variability - rather it is a supporting argument for the claim that judicial style varies and that variation is a fact in itself.

In a 2019 study on questions around oral argument at the US Supreme Court, Dickinson provides the most recent application of computational text analysis to judicial decision-making at the US Supreme Court (Dickinson 2019). To build his predictive models from the transcript texts, Dickinson combined a number of techniques for assessing oral argument question "features" such as: analysis of the number and length of questions, when questions were asked, what sentiment can be attributed to the question, and an $\mathrm{N}$-gram analysis that captures the frequency in the

3 They claim that other stylometric features did not influence the results. 
use of certain words. The analysis was combined to create models for each justice; and each model was then trained against a training set of ten samples of the different feature analyses. The trained models were finally used to predict the voting patterns of justices, which could be done with an overall accuracy of 73 per cent.

In the other recent study, Pauwelyn and Pelc (2019) sought to identify the WTO secretariat's role in the drafting of WTO panel reports. Similar to this chapter, the authors use academic papers of a selective group of panellists (formal authors) and secretariats (unseen actors) to establish a baseline fingerprint for each potential drafter. Although, unlike Dickinson, the training set is not tested against a test set. By using Stylo, an R-package, they conduct an exclusionary analysis, showing that the stylometric influence of the secretariat is statistically significant. They conclude that the secretariat appears to have a large role in drafting.

\subsection{Stylometry and International Investment Law}

In the case under consideration, investor-state arbitration, computational methods and particular machine learning-like approaches are unavoidable. Like other fields, unseen actors play potentially a large role in the authorship of arbitral awards, in which a usually three-arbitrator tribunal determines whether a state has breached certain provisions of an international investment treaty to the detriment of a foreign investor. The remarkable increase in the number of cases brought by foreign investors and which are being decided by a small circle of arbitrators (Langford et al., 2017) increases the likelihood that arbitrators rely on assistants, arbitral institution secretaries and/or members of an arbitrator's law firm to assist in drafting of decisions, orders and awards (see Baetens, 2019).

Stylometric analysis of investor-state arbitration is also relevant for legal, political and policy reasons. Legally, some parties have sought to annul or set aside arbitral awards on the grounds that they were substantially drafted by an assistant to the tribunal (Galagan, 2015). Take the famed Yukos arbitrations, wherein Russia's efforts to set aside the awards in the Dutch courts included claims that the assistant was in fact a fourth arbitrator due to the disproportionately high number of hours that were billed. ${ }^{4}$ Leaving aside the problematic conflation in calling an assistant an arbitrator - billable hours do not necessarily correlate at all to the amount of an award drafted, let alone to a correlation between drafting an award (what an assistant might do) and deciding the outcome (what an arbitrator does) - there may

4 Which doubled those of the Chairman (3,006 to 1,592 hours). 
nonetheless be a tipping point where drafting turns into improper decisionmaking. While the Yukos set-aside relied on billable hours, a stylometric analysis of authorship of the award texts could have been conducted and would have potentially led to a similar, and likely better, finding. ${ }^{5}$

Politically, stylometric analysis may help us determine what members of an arbitral tribunal contributed to a collectively written (the norm across most types of international courts and tribunals) opinion or award, by providing insights into the panel dynamics and political manoeuvring of such authorial collaboration. ${ }^{6}$ In investor-state arbitration, almost all awards are collectively issued by a tribunal of three members. Dissents and separate opinions still remain relatively rare, although decreasingly so in recent years. This consensus-based approach may be viewed as paradoxical in that the parties typically each select their own party-appointed "wing" arbitrator. Yet, while the initial assumption frequently holds that a system of partyappointed arbitrators would be more prone to fragmentation and dissent, ${ }^{7}$ it is often the norm of consensus-building and collegiality that prevails in drafting and deliberations among tribunal members. Common explanations for the prevalence of the consensus norm in investor-state arbitration, and why formal dissents may have less utility (unless wing arbitrators are signalling their positions for future reappointment), ${ }^{8}$ is that party-appointed wing arbitrators are more likely to influence the collective deliberation and writing of arbitral awards if they are more involved in the drafting process. However, for the parties and readers of such awards, it is difficult, if not impossible to know who may have written what parts of the award.

From a policy perspective, understanding the respective arbitral influences on award writing is important for analysing the likely effects of current policy reform processes that seek to push investor-state arbitration closer to a permanent court system without party appointment. Stylometric analysis may help states and reformers predict what a shift to a judge-centric system might mean by better understanding the role of wing arbitrators. ${ }^{9}$ Moreover, we may also want to simply know how arbitral resources are allocated in the award drafting process, including how the distribution of tribunal fees between wings and chairs (chairs are

\footnotetext{
See, e.g., Yuen (2017).

And earlier in the USA: see Urofsky (2017).

On affiliation bias due to party appointment, see Puig and Strezhnev (2017).

See discussion in Langford and Behn (2018) on reappointment strategies.

9 This is because we do not know whether a decision favourable to a claimant, for example, was the result of (1) the respondent wing having little influence; (2) the respondent wing preventing an even more pro-claimant result; or (3) other factors beyond the party appointment.
} 
almost exclusively allocated a higher percentage of fees than the wings $)^{10}$ may or may not affect expected workload.

Moving beyond the domain-specific uses, the recent digitization of the jurisprudence contained in international arbitral awards, our comprehensive database with structured data and the rise of new stylometry programmes provides the possibility for new forms of stylometric analysis and machine learning applications. In the past few years, qualitative insights in stylography have been incorporated into software packages in Python and $\mathrm{R}$. This means that we can analyse instantly hundreds and thousands of legal decisions in order to determine the potential author or share of contributions from different authors. Indeed, international investment treaties have already shown themselves susceptible to both automatic text analysis and machine learning (Alschner and Skougarevskiy, 2016).

However, automated text analysis of jointly authored arbitral awards provides a polycentric challenge. An arbitral award - equivalent to a court judgment - in any given investor-state arbitration case is issued by three "seen" actors and we do not know whether variations in the award might represent the influence of "unseen" actors (assistants to the tribunal, clerks to the arbitrators and arbitral institution secretaries), "seen" actors (claimant and respondent wing arbitrators) or both. In the first iteration of our research, we tried a comparative approach to stylometric analysis. We measured the similarity of tribunal awards written by the same chair. However, like Pauwelyn and Pelc in the first part of their paper, we found that this method was noisy. We could not distinguish the work of different members of the tribunal - cosine similarity scores were difficult to compare across arbitrators. Thus, we moved to a prediction-based model and using different baseline documents, this chapter represents a first step in determining authorship using the Java Graphical Authorship Attribution Program (JGAAP) (Joula, 2009).

The main aim of this chapter is methodological. We seek to develop and showcase a stylometric analysis of opinions that moves beyond function words, tests new software, and most importantly applies machine learning logics that seek to predict the degree of authorship. In this chapter, we describe a computational model that seeks to calculate the stylometric distance scores between an arbitrator's single author writings (principally both academic articles and individual procedural orders) and the awards

10 Does authorship follow the money? This might be expected given that chairs are paid disproportionately more than wings on account of the expected workload. Or does it follow influence and are some wings particularly influential? Parties spend considerable time trying to appoint wings that might both reflect their preferences and exert significant influence. 
emanating from tribunals they chair. There is an underlying assumption here that in any given arbitral tribunal, the chair of the tribunal is the lead in the drafting process of the award.

To create our model, we first develop a stylometric algorithm on single author writings ("training set") and then seek to predict the actual author of the award. This analysis results in a distance score that allows us to determine whether some arbitrators' awards bear less resemblance to their other writings. The lesser the resemblance to other writings, the more likely that the award is being written with input from the wing arbitrators and/or assistants and arbitral institution secretaries. The empirical focus in this chapter is on the nine most prolific presiding arbitrators, whom we introduce in the next section. Future research will concentrate on a broader range of chairs plus a calculation of distance scores for wing arbitrators in order to assess their influence.

\section{THE INVESTOR-STATE ARBITRATION REGIME}

\subsection{The Regime}

The development of the modern international investment regime represents a remarkable extension of international law in the post-war period. Built on a network of more than 3,500 signed bilateral investment treaties (BITs), regional free trade agreements (FTAs) ${ }^{11}$ and a handful of plurilateral investment treaties, ${ }^{12}$ it gives foreign investors various substantive protections and commonly the right ${ }^{13}$ to investor-state dispute settlement (ISDS).

Arbitration commonly arises when a foreign investor alleges that the beneficiary rights granted under an international investment agreement (IIA) have been breached by the state hosting its investments. For example, Phillip Morris challenged (unsuccessfully) tobacco regulation in

11 UNCTAD provides an extensive database on IIAs, available at: http:// investmentpolicy hub.unctad.org/IIA (accessed 15 March 2017).

12 Prominent examples include: North American Free Trade Agreement (NAFTA) (1994); Dominican Republic-Central American Free Trade Agreement (DR-CAFTA) (2005); Comprehensive and Progressive Agreement for TransPacific Partnership (CPTPP) (2018), replacing the Trans-Pacific Partnership (TPP); US-Mexico-Canada Agreement (USMCA) (2020) replacing NAFTA.

13 IIAs typically include the following types of protections to foreign investments: prohibitions against expropriation without adequate compensation, full protection and security, fair and equitable treatment (FET), most-favoured nation $(\mathrm{MFN})$ treatment, and national treatment. 
Australia ${ }^{14}$ and Uruguay, ${ }^{15}$ on the basis that it infringed their intellectual property rights while shareholders in Yukos challenged (successfully) the Russian government's taxation litigation against the company, which precipitated its eventual bankruptcy. ${ }^{16}$ However, for comprehensiveness, investor-state arbitration is not exclusively treaty-based, but also occurs in cases between foreign investors and host states according to contractbased arbitration agreements allowing for investor-state arbitration ${ }^{17}$ or investor-state arbitration provisions embedded within national foreign direct investment (FDI) laws.

The number of investor-state arbitrations has increased exponentially over the past two decades: see Figure 3.1. The data comes from our Pluricourts Investment Treaty and Arbitration Database (PITAD) in which we have tracked and coded all known cases. ${ }^{18}$ It is this meteoric rise

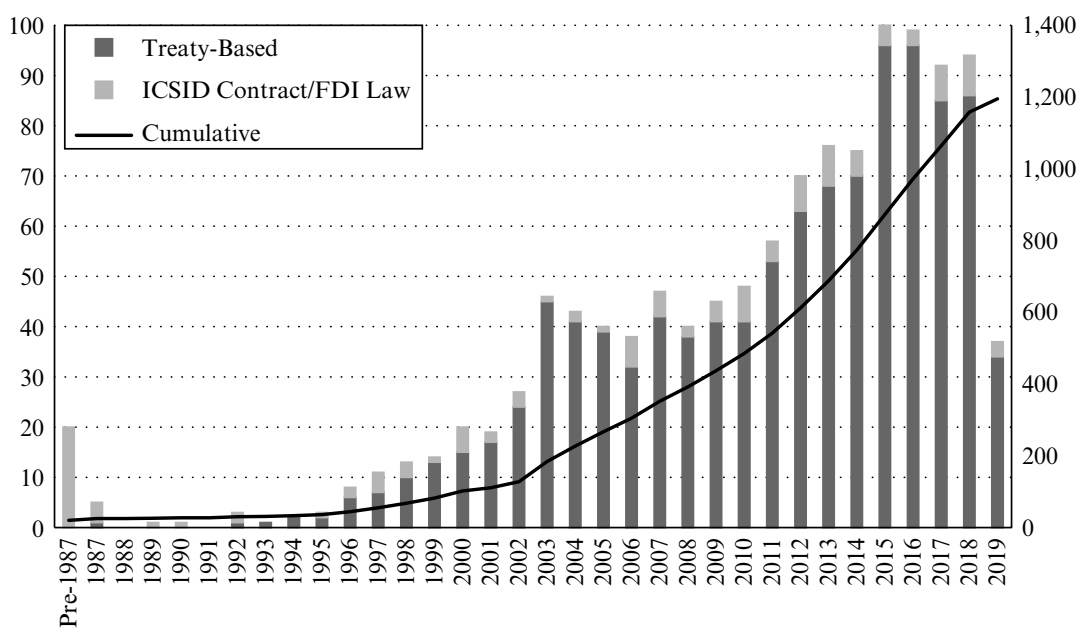

Figure 3.1 Investor-state arbitration cases registered by year $(1987-2019)^{19}$

14 Philip Morris Asia v Australia, PCA Case No. 2012-12, Jurisdiction Award (27 December 2015).

15 Philip Morris Brands v Uruguay, ICSID Case No. ARB/10/7, Award (8 July 2016).

${ }_{16}$ The three landmark cases collectively granting 50 billion USD to Yukos shareholders: Yukos Universal v Russia, PCA Case No. AA 227, Award (18 July 2014); Hulley Enterprises v Russia, PCA Case No. AA 226, Award (18 July 2014); Veteran Petroleum v Russia, PCA Case No. AA 228, Award (18 July 2014).

17 As embedded in various forms of investment contracts or concessions.

18 Behn et al. (2019); Behn et al. (2018).

19 PITAD, ibid.; 831 cases in total through 1 January 2017. 
in the instances of investor-state arbitration over the past two decades that has led some to claim there is "no other category of private individuals" that are "given such expansive rights in international law as are private actors investing across borders" (Simmons, 2014, p. 42).

By the end of the first decade of the 2000s, the use of investor-state arbitration had emerged as a global, prominent and lucrative area of international adjudication, while at the same time coming under increasing scrutiny from a growing number of states, scholars and civil society actors (Waibel et al., 2010). Not all of the cases have been concluded and claimant-investor success rates vary. Of the 1,232 investor-state arbitration cases that have been registered as of 1 June 2019, claimant-investors have won on the merits in 47.2 per cent of cases.

\subsection{The Actors}

Investor-state arbitration involves a range of actors - arbitrators (wings and chairs), legal counsel, expert witness (legal and quantum) and arbitral institution secretaries/assistants to the tribunal. Each party to the dispute will appoint one of three arbitrators; and in most cases the parties (or the co-arbitrators) will jointly appoint the chair. There is, nonetheless, a large degree of variation in the manner of appointment. While the default is that the parties will appoint the two wing arbitrators, the chair can be appointed by the parties, the two wing arbitrators or by the institution hosting the arbitration. For International Centre for Settlement of Investment Disputes (ICSID) annulment cases, all three annulment committee members are appointed by the Secretary-General of ICSID. Of all the possible configurations for the appointment of arbitrators in investorstate arbitration cases, however, there is an underlying constant. This structure means that for every arbitration, there are individuals (either the parties, legal counsel representing the parties, arbitral institutions or co-arbitrators) that are making selection decisions.

Drawing on a study we produced in 2017, the top 25 arbitrators by numbers of appointments at that time are listed in Table 3.1 (Langford et al., 2017). There is a familiar pattern of well-known grand old men and two "formidable women" (Stern and Kaufmann-Kohler), as Puig (2014) christened them. Most of these top 25 arbitrators also have a sizeable number of influential and prestigious presiding chair appointments. The prominent chairs selected for this study are highlighted in italics in Table 3.1 (except for Andres Rigo Sureda and Gilbert Guillaume, who are in the list of top 10 chairs but are not on the list of top 25 arbitrators by any type of appointment)).

In addition to the number of prominent chairs singled out for the purpose 


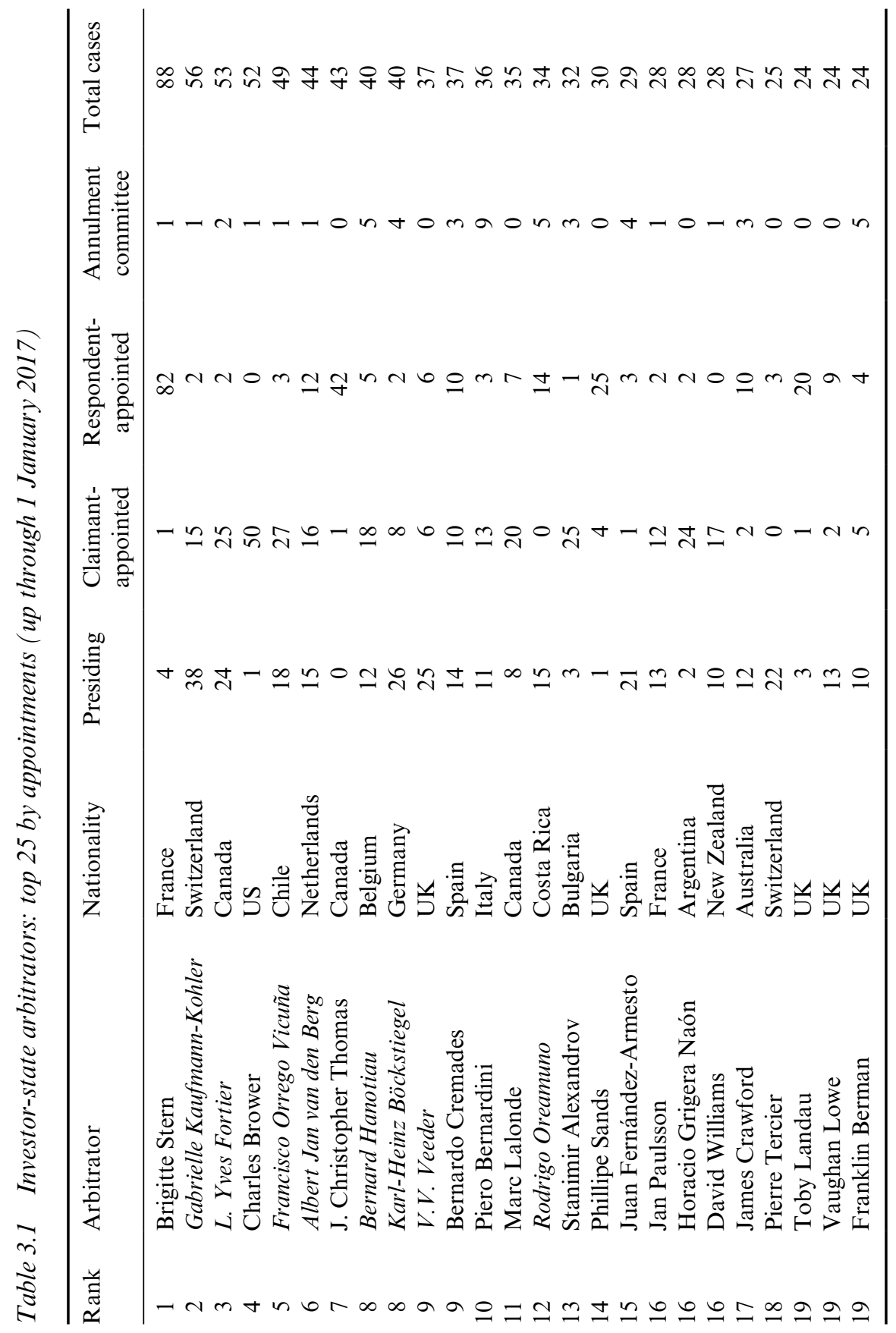


of this "proof of concept" study, later iterations may seek to identify the degree of authorship among the wing arbitrators in any given case as well as chairs of lesser caseload than the top 10 chairs selected here. While the number of arbitrators attributable to particular individuals is very high among known investor-state arbitrations, the names and roles of the various unseen actors is decidedly less so. PITAD includes data on the role and name of individuals acting as arbitral institution secretaries as well as data on assistants to the tribunal where disclosed. While often invisible to the outside world, it is often argued that these assistants and secretaries shape and influence different types of international litigation. While earlier studies indicated that the role of an arbitral institution secretary ranged from no drafting to certain non-substantive parts of award drafting (NYC Bar Association, 2006, p. 585), recent accounts suggest that some arbitral institutional secretaries may be more influential (St. John, 2016), but that tribunal assistants are almost assuredly doing significant drafting in certain instances. ${ }^{20} \mathrm{In}$ PITAD, there is data on these assistants and secretaries in 568 cases.

\section{METHOD}

\subsection{Corpus Selection: Awards}

In the first iteration of our stylometric analysis, we adopted the following research design. The aim was to first determine the extent of variation and distance between a chair's award in investor-state arbitrations and a "baseline" of their "personal" writing. This approach cannot disclose whether it is assistants/secretaries or certain wing arbitrators that have also contributed to a chair's award. Rather, it is the first step in identifying whether there is significant variation in some select chair's awards that merit closer quantitative and qualitative examination (to be undertaken in a second iteration).

For this initial pilot study, we have a sample corpus of arbitral awards that maximizes the number of documents that can be analysed. We began by determining the ten most prolific arbitral chairs to date in investor-state arbitration (all treaty-based cases but also ICSID contract-based and FDI law-based cases, and annulment committee decisions). We identified those chairs that have rendered the most final awards (whether a dismissal for lack of jurisdiction or a determination on the merits of the claims). In

20 See also in relation to the WTO: Pauwelyn and Pelc (2019); Langford et al. (2020). 
addition to limiting this list to only finally resolved cases, we restrict the sample to identify chairs with the most final awards that are publicly available, and that were written in English. We also include annulment committee chairs where decisions are concluded, public and in English. From these criteria, we are able to select our list of the top 10 chairs. The full set of decisions is set out in the online Appendix ${ }^{21}$ and the available corpus is summarized in Table 3.2. From this list, Rodrigo Oreamuno is not analysed because no academic writings in English could be determined.

With these nine arbitrators identified, we created a corpus of investorstate arbitration awards that correspond to each of the cases where each of these arbitrators acted in the role of chair. The number of awards can be higher though when there are multiple awards per case: for example, Gabrielle Kaufmann-Kohler has 17 cases where she was chair that meet the criteria but 38 documents that can be considered awards. There are some jurisdictional awards in addition to final awards in bifurcated cases that we included (as well as interim awards, and cost awards, and so on); and we also included a few jurisdictional awards in cases that ultimately settled or a final award remained pending. ${ }^{22}$

In terms of text for the stylometric analysis, we decided to leave the entire award intact in this iteration. This is because we are partly interested in the overall contribution of different actors (as measured as the likelihood of chair authorship); and different actors are hypothesized as contributing to particular types of texts within each award (e.g., arbitral institution secretaries may produce procedural histories, an assistant to the tribunal drafting the summaries of the position of the parties, and the arbitrators (both the chair and wings) drafting the sections labelled as analysis of the tribunal). Using the award completely intact may be able to show which chairs write more of an entire award; it may not allow for understanding what parts are written by authors other than the chair.

An alternative way is to section the award into parts; and then to analyse each part stylometrically around the most likely type of author for each part. This can be done by looking at the whole award, but with identifiers for each part. Or one could discard all parts of the award except

21 Available at: https://pitad.org/assets/Langford_et_al_Stylometrics.pdf.

22 These cases were not included in the count to identify the top 10 chairs, but they can be included in the corpus of "awards" rendered by that person in the analysis. Moreover, we only counted one award on jurisdiction and one award on merits for Fortier in the Yukos cases - these are three cases in the selection criteria but six "awards" for the analysis. But in this case, we only used one of the jurisdictional awards and one of the merits awards (because they are identical but for the amount of damages and the names of the parties). 


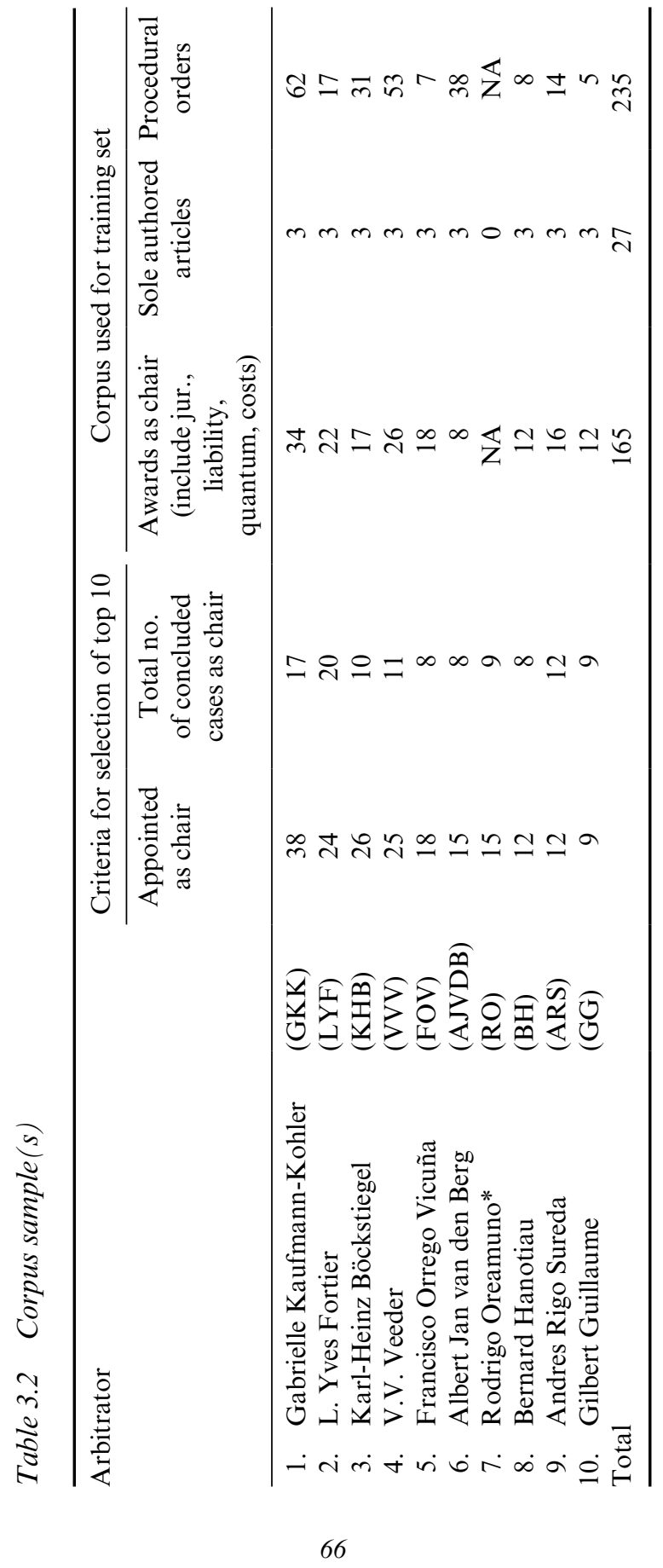


the part identified as most likely to be written by a particular type of actor. A typical investment arbitration award will contain a number of different parts, which might include sections such as: statement of facts, procedural history, summaries of the positions of the parties, and analysis of the tribunal. Additional portioning of the award could remove parts irrelevant to the identification of authorship such as titles, table of contents, information about the parties, addresses, technical annexes, and so on; and finally, it may be useful to portion out citations and quotations in order to reduce text that is known to be the least likely to carry stylometric fingerprints (however, there is an argument that citations may expose patterns of use that could be an identifier of style even if the actual text is not).

We will test these various alternatives in the future. In addition, a final way to dissect investor-state arbitration awards is by paragraph - which we have recently delineated in the text corpus. This will enable us to move from a document-based approach to a paragraph-based approach, which will permit a more fine-tuned stylometric analysis.

\subsection{Corpus Selection: Baselines}

In order to predict the likelihood that an arbitrator wrote a particular award, we used three baselines of comparable style: academic articles, procedural orders, and their other awards as chair. For each arbitrator, we collected three academic articles which arguably provide the best indication of an arbitrator's "personal" writing style. Of course, an academic article cannot be fully representative. It may have been edited or even partly drafted by an assistant and the academic genre of writing is clearly different, at least teleologically, from the arbitral genre.

Procedural orders are quite likely to reflect a presiding arbitrator's "arbitral" style. Many of these are quite long and contain significant tailored and bespoke analysis of particular issues in the case. These orders are usually signed only by the presiding arbitrator, and the preparation of them is a core part of their chair's role in proceedings. To be sure, some of the procedural orders may be written by an assistant, which makes this baseline somewhat endogenous.

Finally, we used as a baseline other awards in which an arbitrator was chair. Of course, this method suffers from even greater endogeneity if wing arbitrators played a substantive role in the drafting of those awards. Therefore, we have run separate and joint models for the three baselines. However, given the hypothesis that chairs take the lead in drafting arbitral awards, then we should expect that there is a fairly close relation between these awards. Greater stylometric distance and variation could indicate other players are involved. 
Ideally, we will have split this corpus in two in order to test the initial stylometric model against a training set. That was not permitted by the software we used (see next sub-section) but we seek to apply such a method in a future iteration (see discussion conclusion).

\subsection{Stylometric Method}

As foreshadowed, we have chosen software that examines a broad palette of stylistic features. JGAAP (Joula, 2009) allows extensive analytical customization, such as canonicizers (normalization of texts), analyses function words, ability to sort on word and sentence length, lexical frequencies, punctuation patterns, rare words, first word in a sentence and part-of-speech. Its primary claim to fame is the identification of the ghost novel by J.K. Rowling (Coyne, 2013) although it is not particularly suited to high-volume computational analysis.

While the broad palette of analysis gives further depth to the analytics, it also adds more complexity. To navigate this increased complexity, JGAAP analyses the text in three stages. First, a set of event drivers is applied to each of the training sets and target awards. Each event driver represents a specific method for determining the author. This could be word choice, sentence length, punctuation and so on. Second, the output of each event driver is cumulated in the event culling mechanism, whereby each factor is weighed according to an information gain algorithm, where the event drivers that contribute the most significant contributions to identifying the author are selected. In this second stage, there is a recursive reapplication using several algorithms, including K-means, Markov chain analysis and voted perceptrons on the material as a whole, until the closest match between the texts with unknown authors and known authors is found. Third, the output from stage two is represented as the distance between the known and unknown texts for each possible author. For each iteration the system learns which factors are the most significant identifiers for each document, author and event driver. When this distance iteratively across all texts and authors is minimized to the smallest distance the algorithm stops and outputs the distance of each document to each author. The recent study by Pauwelyn and Pelc used Stylo, which works on a principle of grouping n-grams and comparing these combinations (Eder et al., 2016). However, such a methodology may be vulnerable to common language and drafting standards as well as secondary copy-editing. In this chapter we utilize a broader set of features to enhance the quality of the initial accuracy of the identification. 


\subsection{Stylometrics as a Tool for Legal Scholarship}

As discussed above, so-called "invisible actors" are a simple fact of life in virtually all institutional settings; these actors operate in high numbers in public and private legal institutions around the world, including judiciaries at both the national and international levels. From the clerks and secretaries mentioned above to junior lawyers preparing briefs for senior partners, these actors contribute to the legal reality, and often to the outcome of any given case. While the presence of these actors is not a subject of dispute, their influence and impact is often hard to pin down.

The invisibility of certain actors in the legal output of the arbitral tribunals creates therefore a particular challenge when applying stylometric methods to investor-state arbitration awards. A single paragraph alone may be drafted by a clerk working for one of the wing arbitrators, then reworked and revised by the assistant to the tribunal, before either being edited, or perhaps completely rewritten by the chair of the tribunal with additional review by both wing arbitrators, followed on with proofreading by an arbitral institution secretary. The text may then subsequently be continually edited and modified by all three arbitrators after deliberation, or linguistically corrected and normalized by arbitral institution staff prior to circulation to the parties. When observing an award as a whole - the mixture of text borrowed from the parties, citations of other practice, dry facts of the case, summaries of the parties' positions, and procedural histories - one may perceive an attempt at any coherent analysis as a futile endeavour. Viewed together with the kakophonia of potential authors on any one judicial judgment or arbitral award, stylometrics as a tool of empirical truth in legal decision-making may be justifiably questioned. There is, however, a significant difference between the works of J.K. Rowling and an arbitral award - a claimed author. ${ }^{23}$ As we may know who should be the author or even the authors, we argue that a fruitful use of stylometrics applied to legal decision-making is not the absolute function of author attribution, it is also the study of variance within a single author's written works and decisions. By analysing the degree of variance, we argue that two useful facets of information may be extracted.

The first facet identified is the general variance between the author's (arbitrator's) works compared to the general variance of other authors (arbitrators). We argue that when an author has a greater stylometric variance in their authorship, it is less likely that the work is solely a product

23 At least an assumed one, as it is common and expected that the president of the tribunal also drafts the award. 
of their own pen. By applying a comparison of general variance, we also address some of the challenges discussed above. While there are inherent differences in how an arbitral award, a procedural order, an interim decision and an academic article is written, we presuppose that arbitral awards written by the same author (default presumption being the chair of the arbitral tribunal) have roughly the same writing styles. The elements in the awards themselves are also expected to have vaguely similar distribution of quotations and other elements not attributed directly to the author.

The second facet is the identification of outlier cases that warrant further qualitative study. We are of the opinion that in the field of law, empirics alone are not sufficient to explain the vast complexities of the legal world. It should rather be used as a tool of nuance, correction and factor identification. By highlighting that a case is stylometrically different from other works, qualitative studies may be applied to understand why this is the case, even if the case did not warrant further study when investigated in isolation.

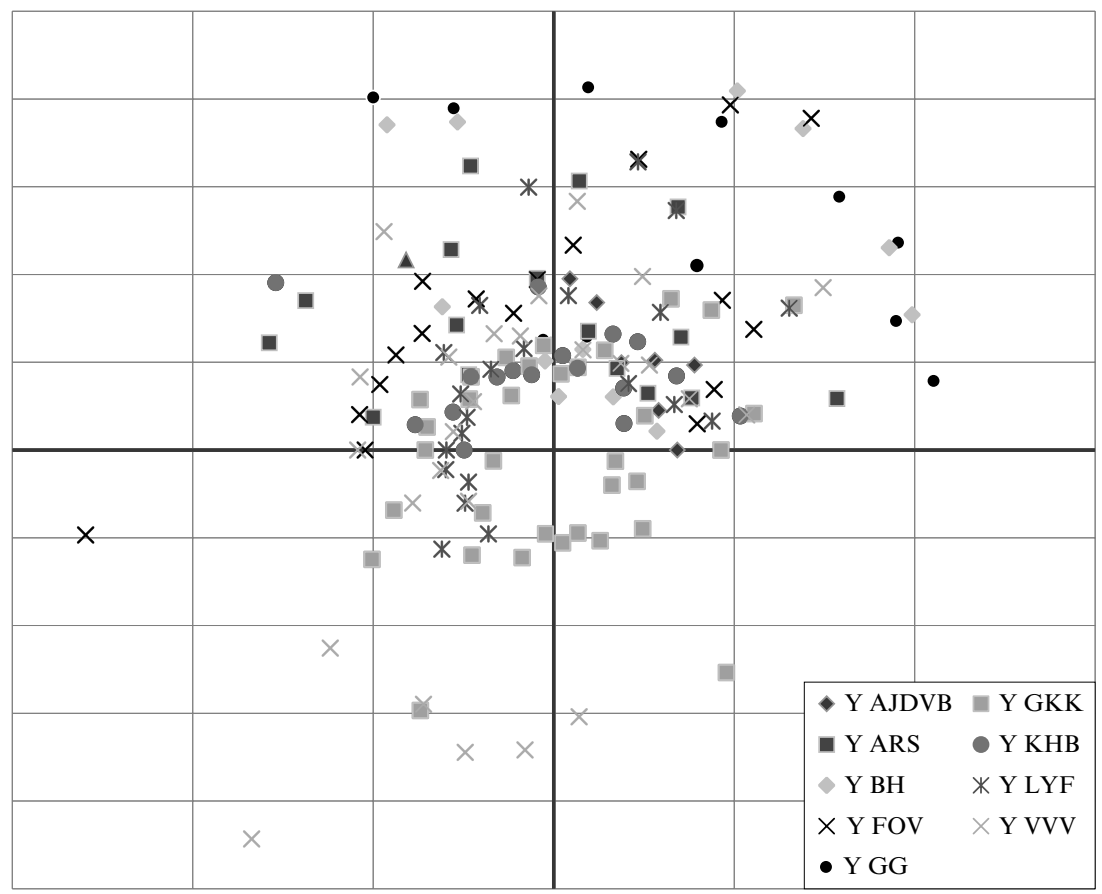

Figure 3.2 Distance and variation: baseline-academic articles and procedural orders 


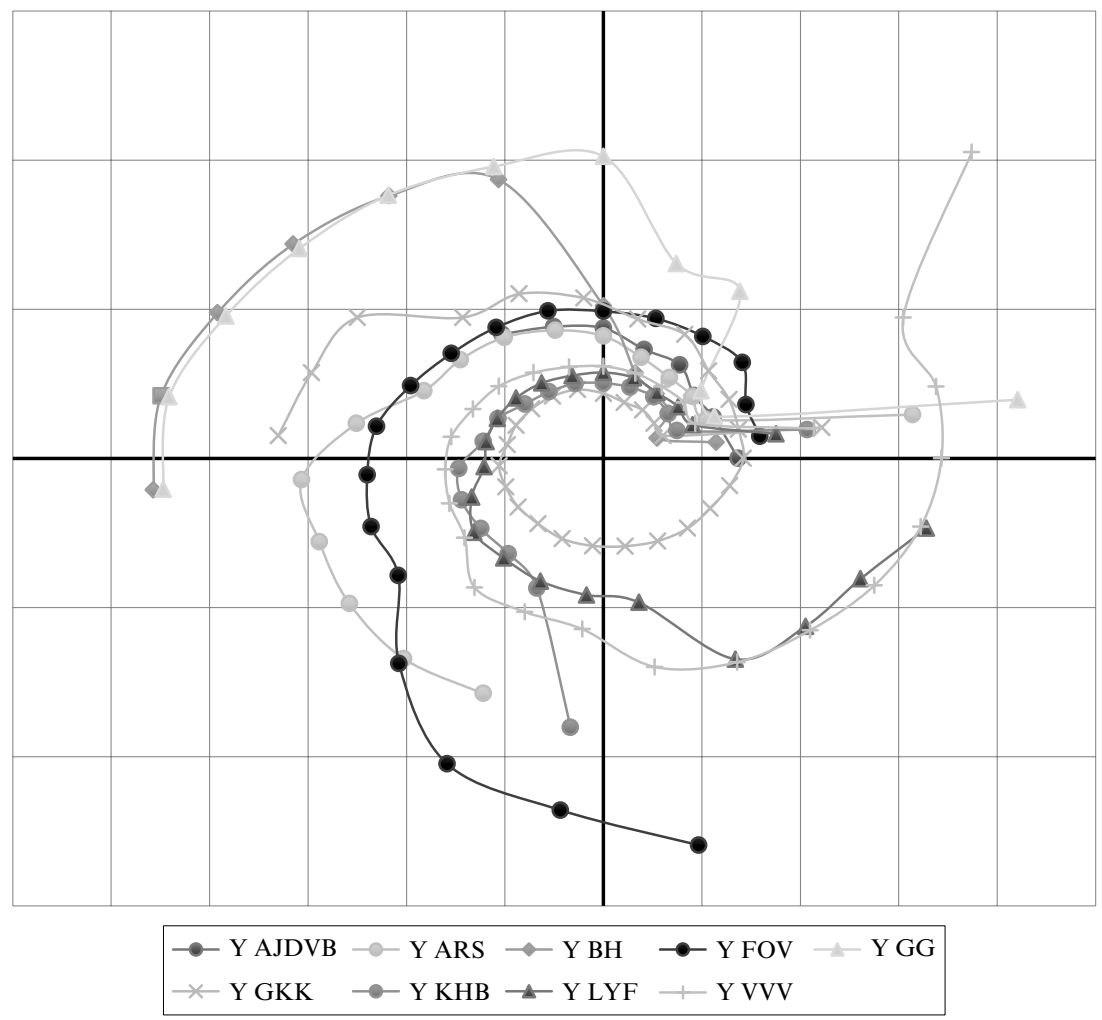

Note: Guidelines are provided for readability.

Figure 3.3 Distance and variation: baseline - academic articles and procedural orders (individually sorted by distance from centre)

\section{RESULTS}

The results provide support for the hypothesis that there is variation between a particular chair's writings and their awards; and there is also variation between the awards of different chairs in terms of the stylometric fingerprints of the analysed texts. Figures 3.2 and 3.3 display the results for the baseline of an individual chair's academic articles plus procedural orders - the two most theoretically solid baselines. For each of the awards, the computed distance from the baseline is shown. The placement in a particular quadrant is only in aid of readability - the critical feature is distance from the centre. As can be seen, some of the chairs have presided over the writing of awards that exhibit consistent and clear rings and 
Table 3.3 Distances and rankings per chair

\begin{tabular}{lcccccc}
\hline Arbitrator & $\begin{array}{c}\text { Avg. } \\
\text { distance }\end{array}$ & Max. distance & $\begin{array}{c}\text { Min. } \\
\text { distance }\end{array}$ & $\begin{array}{c}\text { Std } \\
\text { deviation }\end{array}$ & $\begin{array}{c}\text { Predicted } \\
\text { author } \\
\text { rank }\end{array}$ & $\begin{array}{c}\text { Avg. } \\
\text { distance from } \\
\text { predicted }\end{array}$ \\
\hline GKK & 0.191455180 & 0.37502866 & 0.03068823 & 0.042319027 & 5.62 & 0.03 \\
KHB & 0.155873945 & 0.26308688 & 0.05338601 & 0.018107373 & 4.58 & 0.03 \\
AJVDB & 0.074461303 & 0.09876399 & 0.03766525 & 0.001256029 & 1.5 & $<0.01$ \\
LYF & 0.147576233 & 0.27823769 & 0.03170518 & 0.030128427 & 3.13 & 0.02 \\
ARS & 0.185781689 & 0.27579003 & 0.06232185 & 0.026444165 & 7.44 & 0.05 \\
FOV & 0.157429059 & 0.28508759 & 0.08423162 & 0.051104809 & 5.61 & 0.03 \\
BH & 0.178953521 & 0.26270251 & 0.04124230 & 0.078244405 & 5.16 & 0.04 \\
GG & 0.201174781 & 0.26846347 & 0.06683364 & 0.039293022 & 7.33 & 0.06 \\
VVV & 0.193494691 & 0.30096136 & 0.04332618 & 0.075681522 & 5 & 0.04 \\
\hline
\end{tabular}

semi-circles while others appear to have greater variation. It is not unexpected that the distance from the centre varies from chair to chair. While not analysed in detail, we interpret this variance as an expression of the differences in the chair's writing styles between awards, procedural orders and academic articles.

The differences in variation become particularly clear when we compute and compare the standard deviation of distances for each chair. Table 3.3 provides the minimum, maximum and average distances. For some the deviation is very low - for example Albert Jan van den Berg (AJVDB) although this may be a function of the low number of awards analysed. However, the arbitrator with the greatest number of awards (KaufmannKohler (GKK) with 38) had a fairly average standard deviation. On the other hand, Bernard Hanotiau (BH) and V.V. Veeder (VVV) as well as Francisco Orrego Vicuna (FOV) have significantly higher levels of variation between awards, raising questions as to the reason for variation.

An alternative or complementary approach is to examine for every award by an arbitrator which of the nine arbitrators' individual stylometric models is closest to it stylometrically. We would expect that the actual chair for that award would be ranked first every time. The fifth column, however, indicates otherwise. In the case of AJVDB, he is almost always the predicated author for cases in which he is chair - he has the lowest average distance from his own model to his awards (see also the sixth column). For ARS, it is the reverse - he is ranked lowest as likely author for his own awards based on his stylometric model. The other arbitrators fall within this range.

This form of prediction provides interesting results but possibly the clearest indication of the limitations of the approach. This is because 
it suggests that for some arbitrators we may lack sufficient training material - whether quantitatively or qualitatively - for developing the individual stylometric models. Gilbert Guillaume is arguably the clearest example given there are only five procedural orders. Yet, for some arbitrators such as GKK we have an extensive text corpus for developing the individual model.

\section{CONCLUDING ANALYSIS}

This chapter has reviewed existing stylometric analyses of judicial authorship and sought to highlight three new approaches in computational stylometry - the consistent use of a range of stylometric features, new software packages, and the building of individual stylometric models for judges and others to predict the likelihood of their authorship of a judgment.

Our domain study of investor-state arbitration suggests that stylometric variation may be a feature of arbitral awards, suggesting the presence of multiple authorship, particularly in the case of certain chairs (but there is no indication so far that the variation indicating authorship beyond the chair would be contributions from the wing arbitrators or an assistant to the tribunal). Additionally, and given the pilot nature of this study and partly the limitations of computational stylometrics, we cannot yet reach any conclusive results from this study. Regardless, two results and one methodological observation stand out.

First, the variation between the chair's academic articles and procedural orders, in comparison with their awards is significant. This variation raises the question of why the writing styles of the chairs are so different in the different mediums. It may be methodological that the form and content of the documents (training set and awards) are so different that the variation arises as a natural consequence. Or it may be that large parts of such awards are indeed written by others across the board - and that most text is not primarily written by the chair of the tribunal.

Second, within a given chair's work there is substantial stylometric variation. This large internal variation appears odd, particularly considering that the internal variations for a given chair in many cases expand beyond the average difference between awards and baseline materials. We offer three possible explanations for this. First, the particular case may contain large amounts of noise - be it quotes, citations from statements or similar. Second, the wing arbitrators may have made significant contributions to the text, or it may have been subject to significant copy-editing. Third, the chair may have changed the assistants that help in the drafting process. 
These multiple possible explanations bring us to the methodological observation. As a tool of absolute verifiable truths, stylometrics offer little but indications. The revelations of the rather odd patterns we discuss in this chapter, however, may serve researchers on two levels. On the general level, it highlights an unexplained anomaly or chair's written product. Unlike courts, arbitrators are hired as individuals and not institutions, and as such the parties to a particular dispute have legitimate expectations that the arbitrators themselves conduct the legal analysis and writings (although it is likely very unclear the extent to which parties - and even their counsel - understand the distribution of writing and decision-making between the chair and wings in any given arbitration). We argue that further scrutiny and transparency in these practices are warranted. As the investor-state arbitration regime is a very heterogeneous and slow-moving system, such changes may take significant time, and subsequently researchers may have to conduct further studies to ensure sufficient transparency.

On the specific level, this chapter has identified several outlier awards that have large stylometric deviations from the other written works of a particular chair. By using automated methods, such identification is possible even given the thousands of pages analysed. The identification of these "odd" cases allows for in-depth qualitative and statistical analysis of why these cases turn out so different. Some interviews with particular chairs have already commenced and will undoubtedly add some clarity in explaining outlier awards. These in-depth studies may also reveal other hitherto unknown information about the inner workings and panel dynamics of arbitral tribunals.

As a final comment, some of these issues may also be resolved by rerunning the analysis using more sophisticated machine learning techniques such as deep learning - together with a testing phase, a larger training sample, and a more finely grained sample. The latter will provide especially two distinct improvements. First, the number of facets used as identifying marks in each sentence is infinitely increased beyond the ones described in this chapter. Second, increasing the resolution down to paragraphs and including more arbitrators will both increase accuracy as well as clearly identifying various authors throughout the text. While traditional author analysis is a powerful tool of identifying outliers and oddities in the texts, sparring further avenues of research, new approaches to computational stylometry may offer accurate evidence to form solid conclusions. 


\section{REFERENCES}

Alschner, W. and Skougarevskiy, D. (2016). Can Robots Write Treaties? Using Recurrent Neural Networks to Draft International Investment Agreements. In Bex, F. and Villata, S. (eds), JURIX: Legal Knowledge and Information Systems (Amsterdam, IOS Press), pp. 119-24.

Baetens, F. (2019). Legitimacy of Unseen Actors in International Adjudication (Cambridge, Cambridge University Press).

Behn, D., Berge, T. and Langford, M. (2018). Poor States or Poor Governance? Explaining Outcomes in Investment Treaty Arbitration. Northwestern Journal of International Law \& Business 38(3), 333-89.

Behn, D., Langford, M., Fauchald, O.L., Usynin, M., Lie, H., Berge, T., St. John, T. and Kirkebø, T. (2019). PITAD: The Investment Law and Arbitration Database. PluriCourts Working Paper, January.

Bodwin, K., Rosenthal, J. and Yoon, A. (2013). A Statistical Approach to Judicial Authorship: A Case Study of Judge Easterbrook. Advances and Applications in Statistics 37(2), 123-48.

Burns, K. (2006). Bayesian Inference in Disputed Authorship: A Case Study of Cognitive Errors and a New System for Decision Support. Information Science 176(11), 1570-89.

Carlson, K., Livermore, M. and Rockmore, D. (2016). A Quantitative Analysis of Writing Style on the U.S. Supreme Court. Washington University Law Review 93(6), 1461-510.

Choi, S. and Gulati, G. (2005). Which Judges Write Their Opinions (And Should We Care)? Florida State University Law Review 32(4), 1077-122.

Coyne, J. (2013). Duquesne Professor IDs J.K. Rowling as The Cuckoo's Calling Author. Pittsburgh Business Times, 15 July.

Dickinson, G. (2019). A Computational Analysis of Oral Argument in the Supreme Court. Cornell Journal of Law and Public Policy, 28(1), 449-82.

Eder, M., Rybicki, J. and Kestemont, M. (2016). Stylometry with R: A Package for Computational Text Analysis. R Journal 8(1), 107-21.

Galagan, D. (2015). The Challenge of the Yukos Award: An Award Written by Someone Else - a Violation of the Tribunal's Mandate? Kluwer Arbitration Blog, 27 February, accessed at http://arbitrationblog.kluwerarbitration.com/2015/02/27/ the-challenge-of-the-yukos-award-an-award-written-by-someone-else-a-viola tion-of-the-tribunals-mandate/?doing_wp_cron=1591670349.7362859249114990 234375.

Holmes, D. (1998). The Evolution of Stylometry in Humanities Scholarship. Literary and Linguistic Computing 13(3), 111-17.

Joula, P. (2009). JGAAP: A System for Comparative Evaluation of Authorship Attribution. JDHCS 1(1), 233-334.

King, J. and Kutas, M. (1995). A Brain Potential Whose Latency Indexes the Length and Frequency of Words. CRL Newsletter (Ctr. for Res. in Language, UCSD), 1 November.

Langford, M. and Behn, D. (2018). Managing Backlash: The Evolving Investment Arbitrator? European Journal of International Law, 29(2), 551-80.

Langford, M., Behn, D. and Lie, R. (2017). The Revolving Door in International Investment Arbitration, Journal of International Economic Law, 20(2), 301-31.

Langford, M., Creamer, C. and Behn, D. (2020). Regime Responsiveness 
in International Economic Dispute. In Gáspár-Szilágyi, S., Behn, D. and Langford, M. (eds), Adjudicating Trade and Investment Disputes: Convergence or Divergence? (Cambridge, CUP), pp. 244-84.

Menn, L. and Obler, L.K. (1990). Cross-Language Data and Theories of Agrammatism. In Menn, L. and Obler, L.K. (eds), Agrammatic Aphasia: A Cross-Language Narrative (Amsterdam, John Benjamins), pp. 1369-89.

Morgan, S.E. de. (1882). Memoir of Augustus de Morgan by his Wife Sophia Elizabeth with Selections from his Letters (London, Green \& Co).

Morton, A.Q. and McLeman, J.P. (1966). The Man and the Myth: A Study in the Authorship of Greek Prose (New York, Harper \& Row).

Mosteller, F. and Wallace, D. (1964). Inference and Disputed Authorship: The Federalist (Stanford, CA, CLSI).

NYC Bar Association. (2006). Secretaries to International Arbitral Tribunals: Joint Report of the International Commercial Disputes Committee and the Committee on Arbitration of the New York City Bar Association. American Review of International Arbitration 17(4), 575-96.

Oldfather, C., Bockhurst J. and Dimmer, B. (2012). Triangulating Judicial Responsiveness: Automated Content Analysis, Judicial Opinions, and the Methodology of Legal Scholarship. Florida Law Review 64(5), 1189-242.

Pauwelyn, J. and Pelc, K. (2019). Who Writes the Rulings of the World Trade Organization? A Critical Assessment of the Role of the Secretariat in WTO Dispute Settlement. Working Paper, 26 September.

Puig, S. (2014). Social Capital in the Arbitration Market. European Journal of International Law 25(2), 387-424.

Puig, S. and Strezhnev, A. (2017). Affiliation Bias in Arbitration: An Experimental Approach. Journal of Legal Studies 46(2), 371-98.

Rosenthal, J. and Yoon, A. (2011). Judicial Ghostwriting: Authorship on the Supreme Court. Cornell Law Review 96(6), 1307-44.

Seletsky, O., Huang, T. and Henderson-Frost, W. (2007). The Shakespeare Authorship Question. Dartmouth College, 12 December, accessed at https://ho me.cs.dartmouth.edu/ datamining/Final.pdf.

Simmons, B. (2014). Bargaining over BITS, Arbitrating Awards: The Regime for Protection and Promotion of International Investment. World Politics 66(1), 12-46.

St. John, T. (2016). Tribunal Secretaries. PluriCourts Investment Arbitrator Behavior Workshop, Oslo, 25 May.

Tweedie, F.J., Singh, S. and Holmes, D.I. (1996). Neural Network Applications in Stylometry: The "Federalist Papers". Computers and the Humanities 30(1), 1-10.

Urofsky, M. (2017). Dissent and the Supreme Court: Its Role in the Court's History and the Nations Constitutional Dialogue (New York, Pantheon Books).

Wahlbeck, P., Spriggs II, J. and Sigelman, L. (2002). Ghostwriters on the Court? A Stylistic Analysis of U.S. Supreme Court Opinion Drafts. American Political Research 30(2), 166-92.

Waibel, M., Kaushal, A., Chung, K. and Balchin, C. (eds). (2010). The Backlash against Investment Arbitration: Perceptions and Reality (Alphen aan den Rijn, Kluwer).

Yuen, J. (2017). Arbitral Award Written by the Tribunal Assistant, Lexology, 11 December. 